\title{
Experimental analysis of submerged flapping foils; implications for autonomous surface vehicles (ASVs)
}

\author{
J. A. Bowker, N. C. Townsend, M. Tan, R. A. Shenoi \\ Fluid Structure Interactions Group, Faculty of Engineering and the Environment \\ University of Southampton \\ SO17 1BJ UK \\ jab1e08@soton.ac.uk
}

\begin{abstract}
Autonomous surface vehicles (ASVs) have proven effective as ocean observing platforms for maritime operations. In most cases it is advantageous to operate ASVs for extensive missions in order to maximize their cost effectiveness. Such long endurance missions require ASVs to be capable of scavenging ambient energy from the surrounding ocean environment.

Submerged flapping foils are currently utilized as an effective mechanism to convert ocean wave energy directly into propulsion. The authors propose a novel setup whereby these foils can heave relative to the surface vehicle and, through the application of a power take off (PTO) system, can recover a proportion of the incoming wave energy.

Experiments were performed to investigate the coupled response between a surface vehicle and submerged flapping foils within the context of generating power and propulsion from incoming waves onboard ASVs. Results show that the response of a surface vehicle with submerged flapping foils is particularly sensitive to design parameters such as the longitudinal location of the foils and the seakeeping characteristics of the surface vehicle. Through optimising the PTO system, this setup could recover a useful proportion of wave energy for ASV platforms.
\end{abstract}

\section{INTRODUCTION}

Autonomous surface vehicles (ASVs) are constantly exposed to ambient wave energy and efforts towards harnessing this ocean energy have been mostly restricted to wavepropelled boats utilizing the response of submerged flapping foils. The aim of this paper is to analyse the wave induced coupled relationship between a surface vehicle and submerged flapping foils for not just propulsion but also wave energy scavenging onboard ASVs.

Whilst the concept of wave-induced submerged flapping foil propulsion was established almost 120 years ago, the application has not been fully realised until recently with the emergence of ASV technology. Figure 1 shows the cumulative publications relating to wave-propelled boats. An increase in the research area is noted during the 1980s, which is mainly attributable to the research carried out by Isshiki et al. on the principles of flapping foil wave propulsion $[1,2,3,4]$.

MOST (Autonomous Vessels) Ltd have developed a long range endurance wave propelled ASV called AutoNaut, shown in Figure 2 [5]. Through utilizing the wave-induced response of submerged flapping foils at the bow and stern,

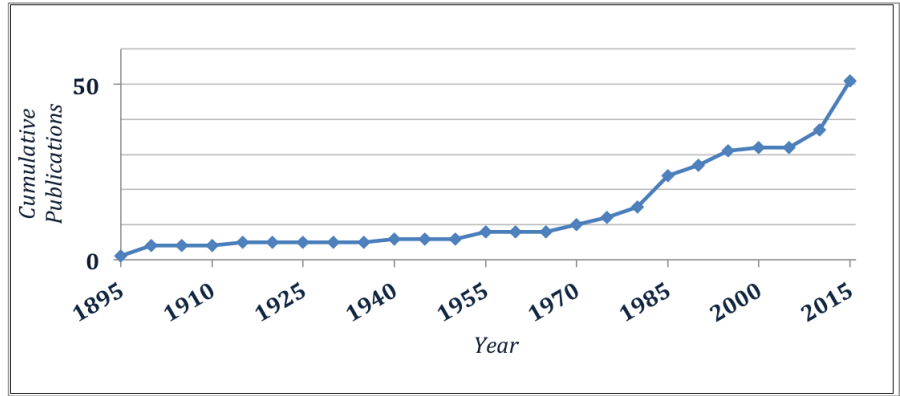

Figure 1: Cumulative publications on flapping foil wave propulsion

AutoNaut propels itself based upon the techniques patented and developed by Linden and Jakobsen respectively [6,7]. The Wave Glider ASV, developed by Liquid Robotics, operates on a similar principle but predominantly harnesses the wave-induced heave motion of a surface float [8]. A series of prototype 'wave devouring' ASVs have also been developed by Terao at the Sakagami Laboratory, which are small catamarans with two submerged foils mounted at the bow [9]. The forward speed of such vehicles is predominantly dictated by the encountered wave energy and current systems follow a circular pattern for station keeping scenarios [8].

The proposed setup, depicted in Figure 3, could alleviate the necessity to follow circular routes for station keeping and, instead, recover wave energy for the powering of onboard systems. If the foils are free to heave relative to the surface vehicle there is minimal induced flow over the foils and the resultant thrust is reduced. In this instance, a proportion of wave energy, which would be converted into propulsion, is absorbed through the relative motion of the foils and harnessed by a PTO system.

\section{A. Wave energy scavenging}

The potential to harvest wave energy for onboard power generation on ASVs or AUVs remains relatively unexplored and requires further investigation. Townsend $(2015,2016)$ has developed a theory and experimental platform to recover wave 
energy. The system is based upon the gyroscopic principle, whereby a spinning flywheel reacts to the wave-induced motions and energy can be captured from the resultant precessional torque from the gyroscopic system [10,11]. Brown et al. (2006) carried out an initial analysis on an inertial energy capture system for an autonomous underwater vehicle (AUV) that involves a mass-spring system combined with a backdriven ball screw generator. The study concludes that a linear magnetic system maybe a more suitable and simple power take-off system [12]. A similar mass-spring theory can be applied for the recovery of wave energy using submerged flapping foils. In this case, a linear magnet generator is regarded as a more effective solution due to the absence of inefficient gearing systems.

\section{B. Wave energy propulsion}

A comprehensive understanding of the coupled dynamics of a surface vehicle with submerged flapping foils is required to inform the design of vehicles solely powered by waves such as ASVs. Figure 3 schematically shows how the wave energy induces the hull motions which is directly coupled with the response of the submerged flapping foils. The wave induced hull motion creates an incident flow velocity and angle of attack at the leading edge of a submerged flapping foil, which consequently generates a propulsive thrust. It is well established that the pitch motion of a vessel in a seaway is significantly reduced due to the presence of a foil submerged at the bow $[13,14]$. With respect to this coupled response between a surface vehicle and submerged flapping foils, previous numerical analysis has addressed the foil location and size. Naito and Isshiki (1986), Beblissakas and Filippas (2015) and Bockmann (2015) showed that, for a ship with a fixed speed in waves, the longitudinal location of the foil has a large effect on the thrust generated and reduction in vessel motions $[15,16,17]$. The experimental analysis of this effect is yet to be carried out and is considered a key aspect in the design of a wave propelled ASV.

\section{COUPLED RESPONSE}

The vessel heave $\left(\eta_{3}\right)$ and pitch $\left(\eta_{5}\right)$ motions in waves are defined by Newtonian equations of motion which combine the inertial, damping, restoring, coupled and forcing terms. The following equations of motion also include the effect of submerged foils by adding terms for the vertical hydrodynamic force $\left(F_{3_{i}}{ }^{F}\right)$ due to the foils and the associated moment about the $\operatorname{LCG}\left(F_{5_{i}}{ }^{F}\right)$ :

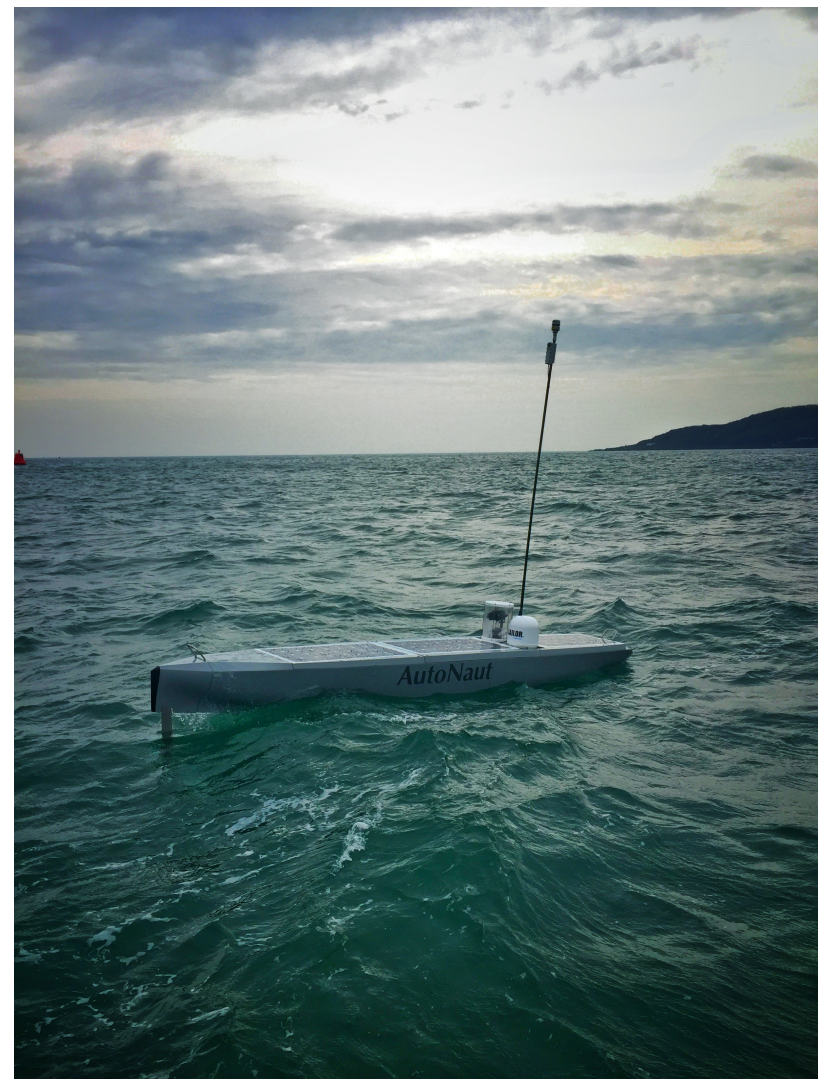

Figure 2: MOST (AV) Ltd ASV; AutoNaut [5]

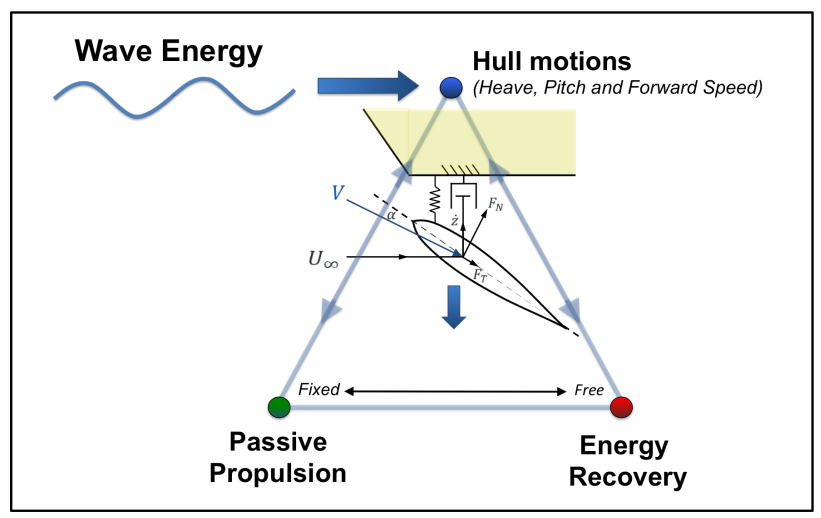

Figure 3: Schematic outlining the research problem

$$
\begin{aligned}
& \text { Heave : } \overbrace{\left(M_{B}+A_{33}\right) \ddot{\eta}_{3}}^{\text {Inertial }}+\overbrace{B_{33} \dot{\eta}_{3}}^{\text {Damping }}+\overbrace{C_{33} \eta_{3}}^{\text {Restoring }}+\overbrace{A_{35} \ddot{\eta}_{5}+B_{35} \dot{\eta}_{5}+C_{35} \eta_{5}}^{\text {Coupled }}=\overbrace{F_{3}{ }^{B}+F_{3_{i}}{ }^{F}}^{\text {Forcing }} \\
& \text { Pitch : } \quad \overbrace{\left(I_{5}+A_{55}\right) \ddot{\eta}_{5}}^{\text {Inertial }}+\overbrace{B_{55} \grave{\eta}_{5}}^{\text {Damping }}+\overbrace{C_{55} \eta_{5}}^{\text {Restoring }}+\overbrace{A_{53} \ddot{\eta}_{3}+B_{53} \dot{\eta}_{3}+C_{53} \eta_{3}}^{\text {Coupled }}=\overbrace{F_{5}{ }^{B}+F_{5_{i}}{ }^{F}}^{\text {Forcing }}
\end{aligned}
$$


where the terms are defined as follows $(i, j=3,5)$ :

$F_{3}{ }^{B}$ - heave excitation force due to waves

$F_{5}{ }^{B}$ - pitch excitation force due to waves

$F_{3}{ }^{F}$ - heave force due to submerged foils

$F_{5}{ }^{F}$ - pitch force due to submerged foils

$M$ - total mass of the vessel

$I_{j}$ - moment of inertia for vessel

$A_{i j}$ - added mass coefficient

$B_{i j}$ - damping coefficient

$C_{i j}$ - hydrostatic restoring coefficient for pure heave

These equations describe the coupled motion whereby the resultant hydrodynamic forces acting on the foils have a significant influence on the hull motions. For thrust generation the submerged foils are forced to oscillate in the incoming waves as shown in Figure 4 a). Consequently a hydrodynamic lift force acts on the foil which, when resolved in the forward direction, combines to overcome the foil drag and hull resistance to drive the vessel forward. Alternatively, the hydrodynamic forces acting on the foil can result in a relative foil motion which opposes that of the surface vessel and can drive a PTO device to recover wave energy, shown in Figure $4 \mathrm{~b}$ ).

The wave induced flapping motion of the submerged foils, combined with the wave orbital particle velocities, generates an incident flow stream at the leading edge of the foil. The magnitude $(V)$ and angle of attack $\left(\alpha_{e}\right)$ of the flow at the leading edge of the submerged foils is resolved as a combination of the vehicle forward speed $(U)$, vessel pitch induced heave velocity $\left(\dot{\eta}_{35}\right)$, vessel heave velocity $\left(\dot{\eta}_{3}\right)$, foil velocity $(\dot{z})$ and the wave horizontal and vertical orbital velocities ( $u$ and $v$ respectively):

$$
\begin{gathered}
V=\sqrt{(U+u)^{2}+\left(v-\dot{\eta}_{3}+\dot{z}+\dot{\eta}_{35}\right)^{2}} \\
\alpha=(\theta+\beta)-\tan ^{-1}\left(\frac{v-\dot{\eta}_{3}+\dot{z}+\dot{\eta}_{35}}{U+u}\right)
\end{gathered}
$$

where $\theta$ and $\beta$ are the foil and vessel pitch angles respectively.

The vector velocity of the flow at the leading edge defines the forces and moments that are exerted about the hydrodynamic centre of the foils. The moment about the hydrodynamic centre of the foil is a combination of the hydrodynamic moment and the lift force acting normal to the chord line at a distance from the foil pivot point. The foil pitch is constrained by a rotational spring and influenced by the added mass due to the heave motion of the foil. The foil heave is either fixed or constrained by a PTO mechanism, which in this case is a permanent magnet tubular linear generator (PMTLG). The PMTLG device is capable of converting linear drive into electrical power through electromagnetic induction; a permanent magnet rod is moved within a series of coils.

In the scenario where the foils are free to heave relative to

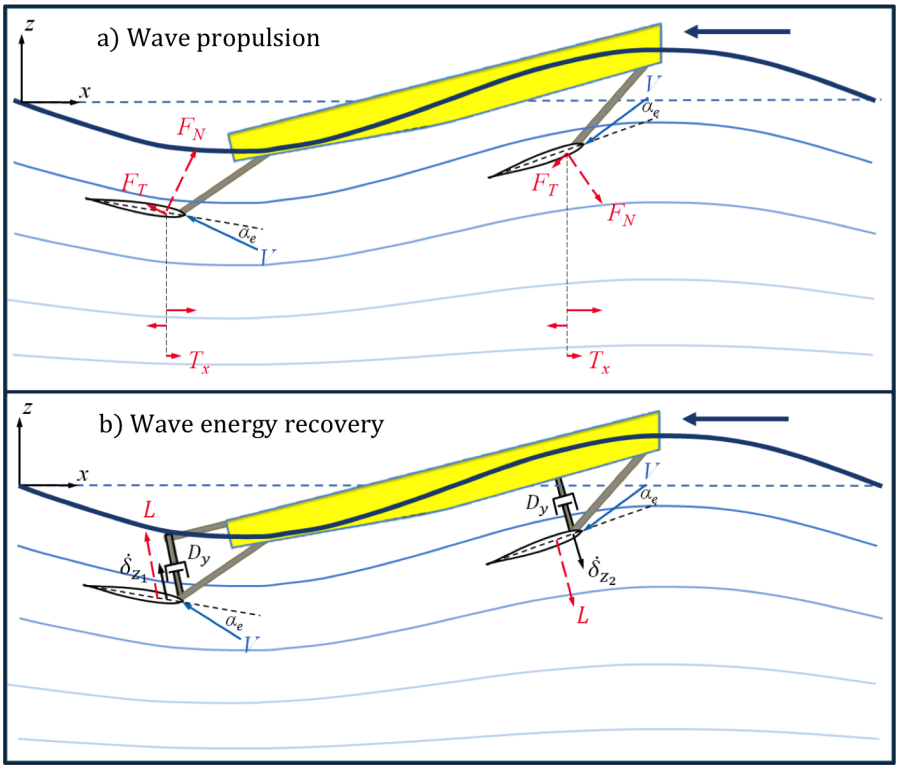

Figure 4: Schematic of wave energy propulsion and energy scavenging

the vessel a hydrodynamic force acts in the vertical direction. The foil is constrained by the damping of the generator and a restoring spring force. The force, $F_{g e n}$, is an opposing electromotive force (emf) exerted on the foil from the generator due to the current induced in the stator coils. For a three phase linear generator the induced voltage at the $i$ th coil is directly proportional to the foil relative heave velocity $\left(\dot{z}_{r e l}\right)$ and the position of the permanent magnet rod (the relative heave of the foil $\left(z_{r e l}\right)$ :

$$
V_{i}(t)=\epsilon_{c} \dot{z}_{r e l}(t) \cos \left(\frac{2 \pi}{w_{p}} z_{r e l}(t)-\delta_{i}\right)
$$

where $\epsilon_{c}$ is the emf constant in $V / m s^{-1}, w_{p}$ is the length of one electrical cycle i.e. the pole width of the permanent magnet and $\delta_{i}$ is the phase difference between each set of coils. For the simplest electrical circuit the generated electrical power can be equated assuming a constant resistance or load $\left(R_{\text {load }}\right)$ [18]:

$$
P_{z}(t)=\sum_{i=1}^{3} \frac{V_{i}(t)^{2}}{R_{\text {load }}}
$$

The opposing generator force can, therefore, be estimated with consideration for the generator efficiency $\left(\eta_{e f f}\right)$ [18]:

$$
F_{\text {gen }}(t)=\sum_{i=1}^{3} \frac{P_{z}(t)}{\dot{z}_{\text {rel }}(t) \eta_{\text {eff }}}
$$

\section{TOWING TANK EXPERIMENTS}

Ideally, the experiments would involve free running (wave propulsion) and station keeping (energy scavenging) tests in waves whereby the response of the flapping foils can be analysed with respect to response of the surface vehicle. The 
free running experiments were made possible by using a rudder to control the heading of the experimental model and, through using a remote control package, the vehicle could be steered up and down the tank. However, the rudder is unable to control the heading of the vehicle during the station keeping scenario and it was, therefore, decided to conduct the wave energy scavenging experiments with the model secured to a towing carriage.

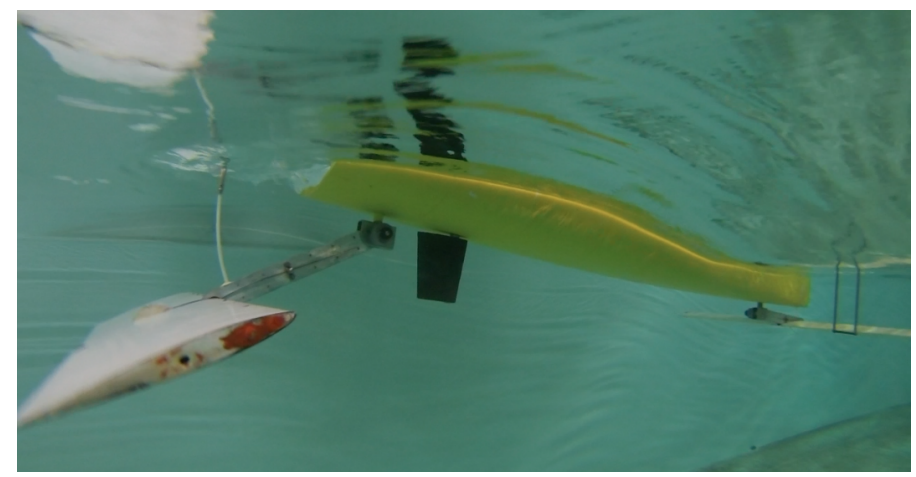

Figure 5: Underwater view of setup with foils free to heave about rotary springs, which are located at the base of the pivot arm beneath the hull

The objective of the free running experiments was to assess the propulsive response of the flapping foil setup in a series of regular waves with an additional aim of capturing the effect of the foil longitudinal locations on the hull motions and corresponding forward speed. The objective of the wave energy scavenging experiments was to also analyse the effect of the foils on the hull motions of the vehicle with a main focus on the power generation response of the submerged foils in waves.

\section{A. Experimental setup}

The experimental model used for the towing tank tests was the same platform used in previous experiments conducted by Bowker et al. (2015) with modifications to install a PTO system[19]. The experimental platform has been fitted with PMTLGs at the bow and stern, which are connected to the foils via flexible rods as shown in Figures 6 and 5.

The foils are mounted at the end of pivot arms and spring loaded in pitch through a bending torque applied by piano wire which is located through the rotating shaft. The spring applies a torque about the leading edge of the foil, which has the following inverse relationship with the pitch angle $(\theta): \tau=$ $10 \times \theta^{-0.15}$. The foils can either be fixed or free to heave about the rotating point beneath the hull (see Figure 5), which houses a set of four springs that work together to maintain the foils neutral depth and apply a restoring force to the PTO setup. The model is also fitted with a rudder which is controlled using a servo and remote control package. Due to the added supporting structure and watertight deck, less ballast weight is added than the previous experiments by Bowker et al. (2015) and totals $25 \mathrm{~kg}$. The hull and foil particulars are detailed in Table I.

Table I: Experimetnal Model and Foil Particulars

\begin{tabular}{|r|r|r|}
\hline Parameter & Value & Units \\
\hline \hline Waterline length, $L$ & 2.27 & $\mathrm{~m}$ \\
\hline Beam, $B$ & 0.3 & $\mathrm{~m}$ \\
\hline Draft, $T$ & 0.1 & $\mathrm{~m}$ \\
\hline Displacement, $\Delta$ & 55 & $\mathrm{~kg}$ \\
\hline Foil chord, $c$ & 0.23 & $\mathrm{~m}$ \\
\hline Foil span, $s$ & 1 & $\mathrm{~m}$ \\
\hline Foil type & NACA0012 & - \\
\hline Foil arm (lengths), $a$ & $0.35,0.9$ & $\mathrm{~m}$ \\
\hline
\end{tabular}

\section{B. Methodology; Wave energy scavenging}

Experiments were performed at the Southampton Solent University towing tank with the model secured to the carriage, which remained at a constant distance from the wave machine. The tank is $60 \mathrm{~m}$ in length, $3.7 \mathrm{~m}$ wide and $1.8 \mathrm{~m}$ deep. The model was free to heave and pitch at the tow post fixing, which was secured approximately $100 \mathrm{~mm}$ aft of the model's longitudinal centre of gravity (LCG). The model was contrained in head waves and the flapping foils were free to move relative to the surface vehicle via the PMTLGs mounted above the foils (see Figure 5. The power cables and hall sensor wires were fed back to the carriage where the position and generated power was recorded. During each test the wave height, vessel motions, relative foil positon and induced voltage was recorded. The tests were repeated three times and carried out in a range of regular waves; at two different waves heights $(0.12 \mathrm{~m}$ and $0.18 \mathrm{~m})$ and a range of wave frequencies $(0.4-1.0 \mathrm{~Hz})$ at increments of $0.1 \mathrm{~Hz}$. In order to analyse the effect of submerged foils on the motions of the surface vehicle, further experiments were conducted with the foils fixed.

\section{Methodology; Wave energy propulsion}

In order to assess the propulsive characteristics of the flapping foil setup, free running experiments were conducted in a controlled environment at the University of Southampton towing tank. The tank is $138 \mathrm{~m}$ in length, $6 \mathrm{~m}$ wide and $3.5 \mathrm{~m}$ deep. The model was tested in head and following regular waves, which were kept at a constant wave height of $0.12 \mathrm{~m}$ and the wave frequency was increased from $0.5 \mathrm{~Hz}$ to $0.8 \mathrm{~Hz}$ at increments of $0.1 \mathrm{~Hz}$. Additional repeat tests were made at $0.7 \mathrm{~Hz}$ to assess repeatability. The foil longitudinal location was changed by approximately $0.6 \mathrm{~m}$ to analyse their effect on the hull motions. The tests assessed the setup with the foils situated at two different locations; firstly, with the foils close to the forward and aft perpendiculars and, secondly, with the foils extended as shown in Figure 6. The model was stationed at the carriage approximately $30 \mathrm{~m}$ from the wave and progressed towards the wave machine in head waves before being turned around and tested in following waves. The approximate period for each run varied from 60 to 180 seconds depending on the 


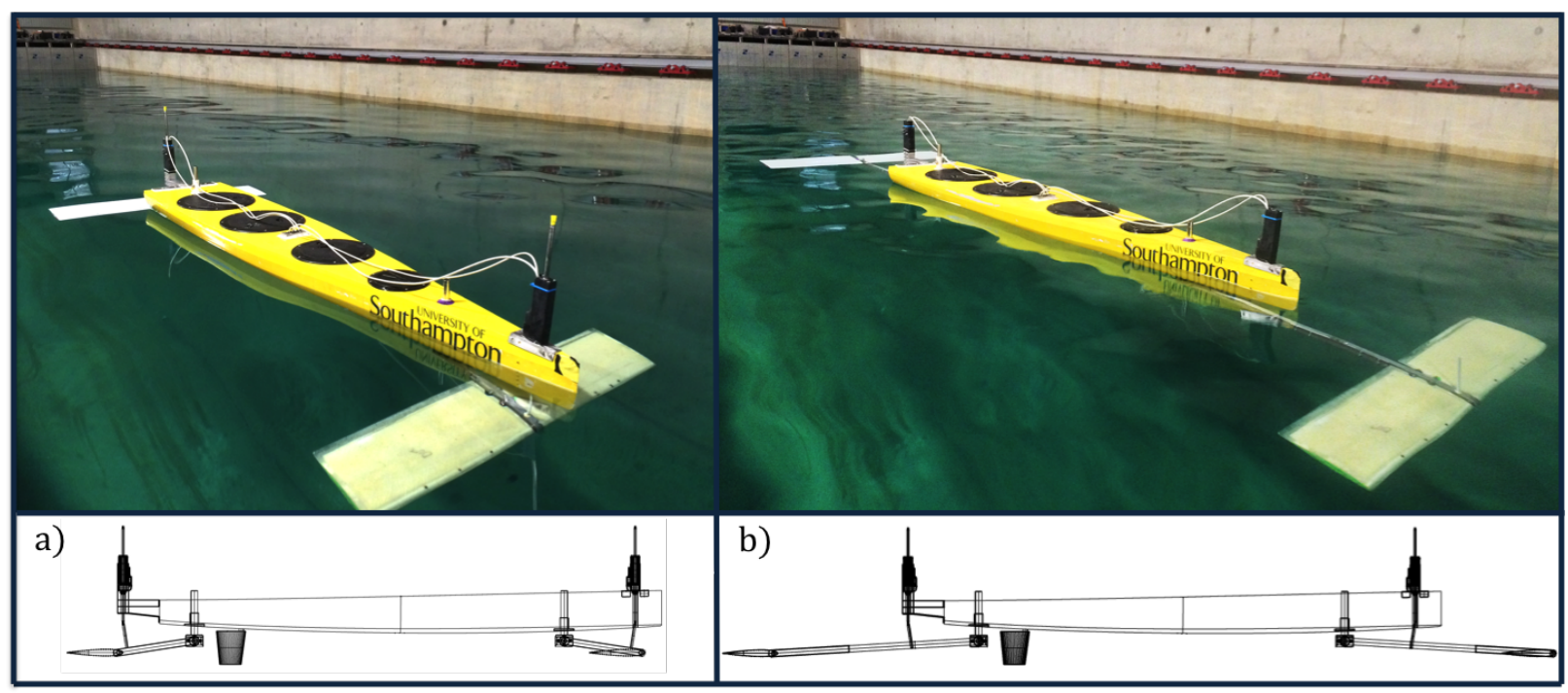

Figure 6: Longitudinal location of foils (at the pivot point from amidships); a) Aft foil $=-1.326 \mathrm{~m}$, Fwd foil $=1.042 \mathrm{~m}$ $\left(L_{L O A}=2.7 \mathrm{~m}\right)$ b) Aft foil $=1.920 \mathrm{~m}$, Fwd foil $=1.646 \mathrm{~m}\left(L_{L O A}=3.8 \mathrm{~m}\right)$

forward speed of the vehicle and the wave reflection from the opposite end of the tank.

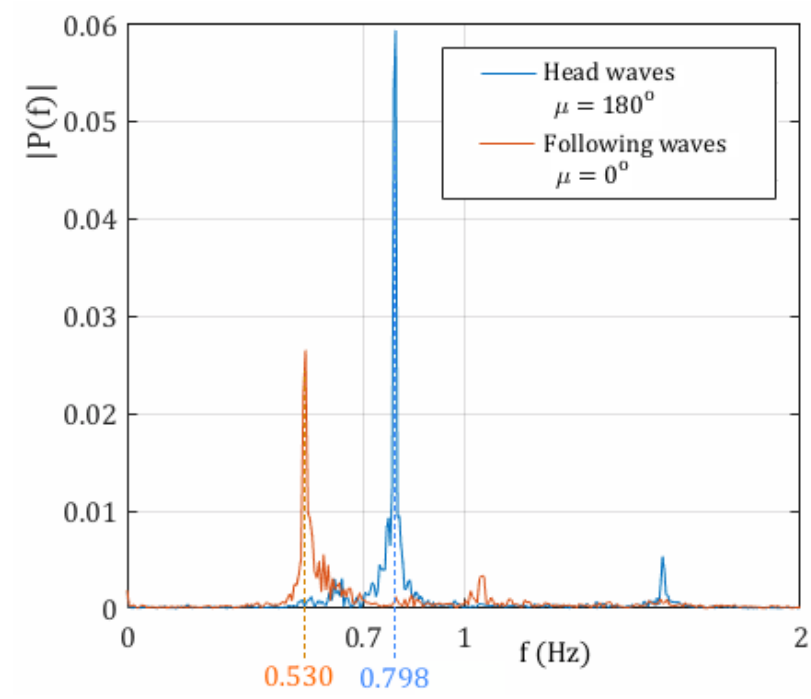

Figure 7: Example fast fourier transfrom analysis of encountered frequency (extended foil condition in a wave of $0.7 \mathrm{~Hz}$ )

An inertial sensor was used to acquire the vessel heave and pitch motions. It was also possible to ascertain the forward speed from the encountered frequency. The sensor was situated approximately at the LCG and VCG (vertical centre of gravity) of the model and data was recorded at a rate of $100 \mathrm{~Hz}$ onto a computer onboard. The output data was in the form of linear accelerations and rotational velocities. The data was filtered using a Butterworth second order filter with a normalized cutoff frequency of 0.01 . However, significant drift errors occurred when converting the surge acceleration data in to forward speed. Performing fast fourier transfrom (FFT) analysis on the data at a specific cut in and out time made it possible to acquire the encountered frequency, as shown in Figure 7. Assuming harmonic hull motions for waves with a wavelength greater than the waterline length of the model, the vehicle forward speed can be calculated from the encountered wave frequency by rearranging the following equation:

$$
\omega_{e}=\omega-k U \cos \mu
$$

where $k$ is the wave number, $\omega_{e}$ is the encountered frequency and $\omega$ is the wave frequency. The heading of the vessel, $\mu$, is given as at $0^{\circ}$ in following waves and $180^{\circ}$ in head waves. Using this technique the forward speed and hull motions could be acquired using a single inertial sensor.

\section{RESUlts}

\section{A. Vessel motions}

Following the assumption that the hull motions are sinusoidal in small amplitude regular waves, it is possible to estimate the amplitude of the motion response from the root mean square (RMS) of the data. As the RMS of a sine wave with unit amplitude is $\frac{1}{\sqrt{2}}$, the amplitude of the hull motions is obtained by multiplying the RMS of the data set by $\sqrt{2}$. Applying this technique to the data acquired in the constrained condition allows for the calculation of motion transfer functions, which are plotted in Figure 8. For the free running experiments, it was necessary to filter and integrate the inertial data before calculating the amplitude of the linear heave and angular pitch displacements, the results of which are plotted as transfer functions with respect to encountered wave frequency in Figure 9. 


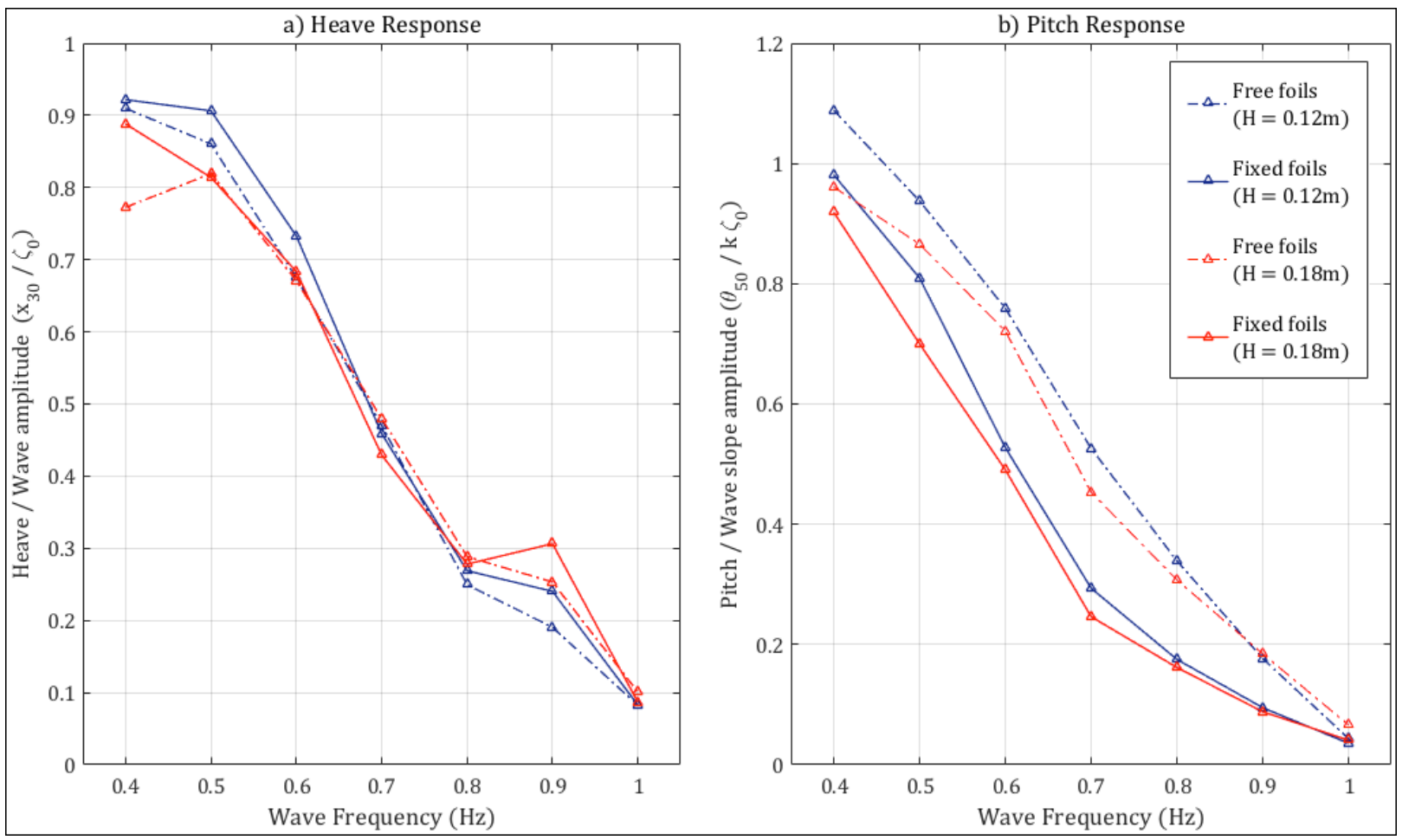

Figure 8: Effect of the foils on the hull motions in the constrained condition (secured to the carriage).

Mean heave standard deviation, $\sigma_{3}=0.0013 \mathrm{~m}$ and mean pitch standard deviation, $\sigma_{5}=0.0019 \mathrm{rad}$
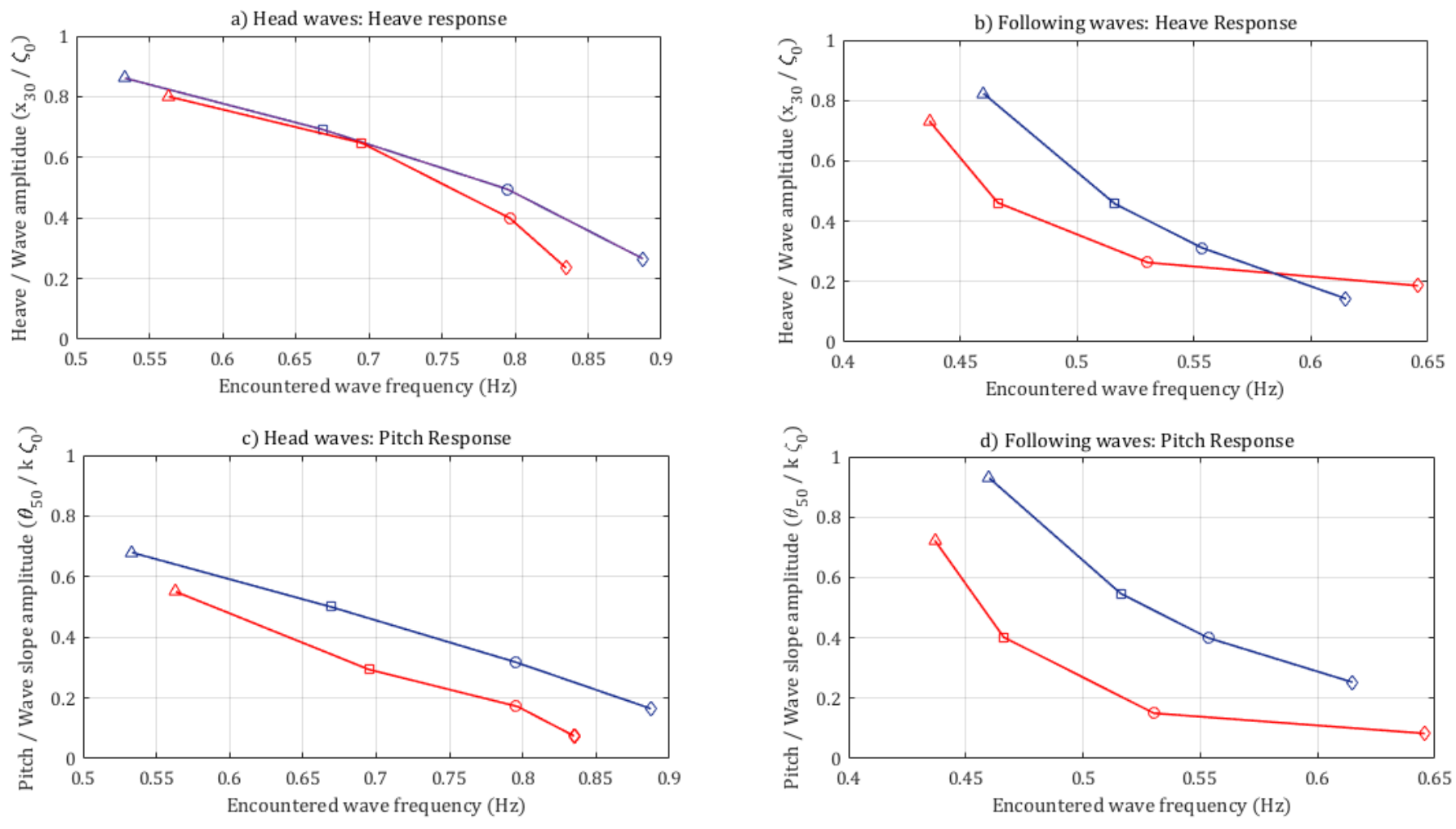

Wave frequency, f: $\triangle 0.5 \mathrm{~Hz} \quad \square \quad 0.6 \mathrm{~Hz} \quad \circ \quad 0.7 \mathrm{~Hz} \quad \diamond \quad 0.8 \mathrm{~Hz}$

Longitudinal location of foils: $\quad-\mathrm{L}_{\mathrm{LOA}}=2.7 \mathrm{~m} \quad-\mathrm{L}_{\mathrm{LOA}}=3.8 \mathrm{~m}$

Figure 9: Effect of the location of the foils on the hull motions in head and following waves for the free running experiments Mean heave standard deviation at $0.7 \mathrm{~Hz}, \sigma_{3}=0.0052 \mathrm{~m}$ and mean pitch standard deviation at $0.7 \mathrm{~Hz}, \sigma_{5}=0.0019 \mathrm{rad}$ 
Table II: Percentage reduction in vessel pitch due to extending the location of the foils (relative to initial foil location at the bow and stern)

\begin{tabular}{|r|r|r|}
\hline Wave Frequency, Hz & Head waves & Following waves \\
\hline 0.5 & $19.0 \%$ & $22.2 \%$ \\
\hline 0.6 & $41.4 \%$ & $26.4 \%$ \\
\hline 0.7 & $46.1 \%$ & $62.4 \%$ \\
\hline 0.8 & $54.9 \%$ & $67.1 \%$ \\
\hline
\end{tabular}

Figure $8 \mathrm{~b}$ ) shows the transfer functions for pitch in regular waves of varying height and frequency. There is a reduction of upto $50 \%$ in the vessel pitch amplitude due to the presence of the foils when in the fixed foil condition. Figure 8 a) shows that the heave motion of the surface vehicle remains relatively unchanged with or without the foils free to move. The free running results in Figure 9 b) further identify the dominant effect of submerged foils on the pitch motion of the surface vehicle. Increasing the longitudinal location of the foils by a factor of approximately $40 \%$ significantly reduces the pitch amplitude in head and following waves, which is summarized in Table II. Figure 9 a) shows that the foil location has a minimal effect on the vessel heave amplitude with respect to wave frequency. However, there is a noticeable shift in the heave motions with respect to the encountered wave frequency, especially for following waves. This indicates that the foils also affect the heave motion of the surface vehicle.

\section{B. Power Generation}

The power generated by each foil was calculated from Equation 6 by measuring the induced voltage over a resistance load of $0.47 \Omega$ on each phase and taking the mean generated power $\left(\bar{P}_{z}\right)$ for each test case. From applying linear wave theory, the input wave power for each test can be estimated using the following definition for wave power $\left(P_{w}\right)$ :

$$
P_{w}=\frac{\rho g H c_{g} b}{8}
$$

where $H$ is the wave height, $c_{g}$ is the wave group celerity or velocity and $b$ is the breadth of the surface vehicle. The energy recovery efficiency can, therefore, be defined as:

$$
\eta_{\text {recovery }}=\frac{\bar{P}_{z}}{P_{w}}
$$

Figures 10 a) and b) show the resulting energy recovery efficiency and peak generated power with respect to wave frequency. Reasonable repeatability is found with the experiment and the same trend with respect to wave frequency is found for both the forward and aft foil. The scavenging of wave energy in this case is shown to be fairly inefficient but this may be due to an suboptimal tuning of the PTO setup. However, the experiments have highlighted several key trends in the application of using submerged flapping foils as wave energy scavenging devices. Most noticeable is the frequency dependent response of the system. Like most wave energy devices there is a significant peak in the generation of power about the resonant motion of the wave energy converter. This is also reflected in the peak power generation but with greater uncertainty due to considering only a single data point for the peak response. For the median wave frequencies $(0.5-0.9 \mathrm{~Hz})$, the mean generated power is almost directly proportional to

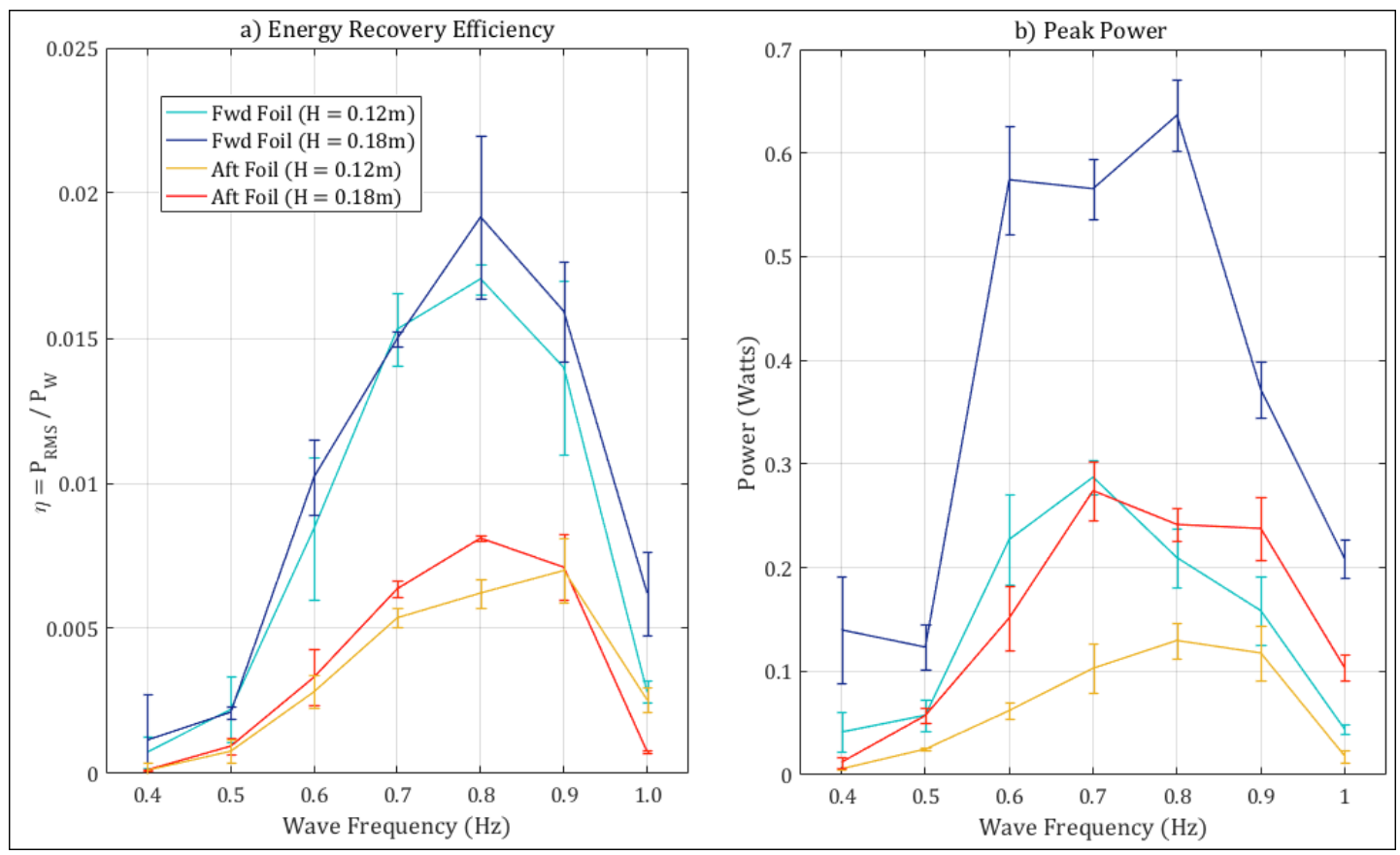

Figure 10: Power generated at waves heights of 0.12 and $0.18 \mathrm{~m}$ over a range of wave frequencies, interpreted as: a) Energy recovery efficiency and b) Peak power generation 


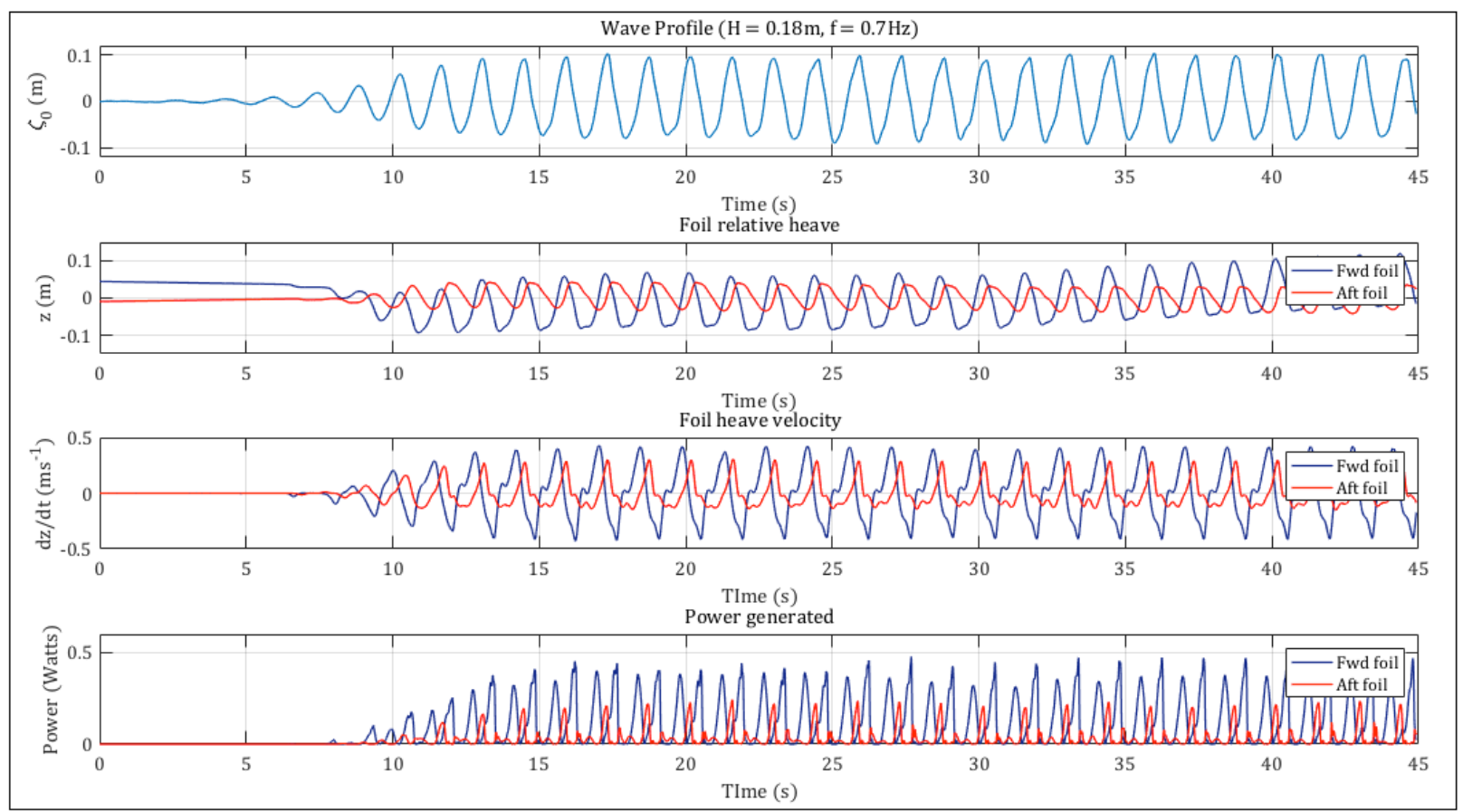

Figure 11: Example time history of wave profile, relative foil motions and corresponding power generation for a regular wave $(\mathrm{f}=0.7 \mathrm{~Hz}$ and $\mathrm{H}=0.18 \mathrm{~m})$

the square of the wave height $(12$ and $18 \mathrm{~cm})$ :

Fwd foil: $\frac{\bar{P}_{18}}{\bar{P}_{12}} \simeq 1.1 \times{\frac{H_{18}}{H_{12}}}^{2}$

Aft foil: $\frac{\bar{P}_{18}}{\bar{P}_{12}} \simeq 0.9 \times{\frac{H_{18}}{H_{12}}}^{2}$

An exemplar time history of the wave amplitude, foil response and power generation is shown in Figure 11. The relative heave velocity of the foil generates the induced voltage in the PMTLG and it can be seen that the forward foil responds at a significantly greater heave velocity compared to the aft foil. It is also interesting to note that the foils operate almost out of phase to one another in this example, but further analysis is required to investigate this with respect to the wave frequency.

\section{Propulsion}

Figure 12 shows the forward speed of the free running model in head and following waves with two different foil locations. Extending the location of the foils has a significantly positive effect on the forward speed of the surface vehicle but only at lower frequencies. At the higher end of the wave frequency range $(>0.7 \mathrm{~Hz})$ the pitch motion of the vessel is significantly reduced due to the extension of the foils, as shown in Table II. This reduction in vessel pitch has an effect on the induced flapping motions of the submerged foils and, therefore, results in a reduction in forward speed at high wave frequencies for following and head waves. At lower frequencies $(<0.7 \mathrm{~Hz})$, the forward

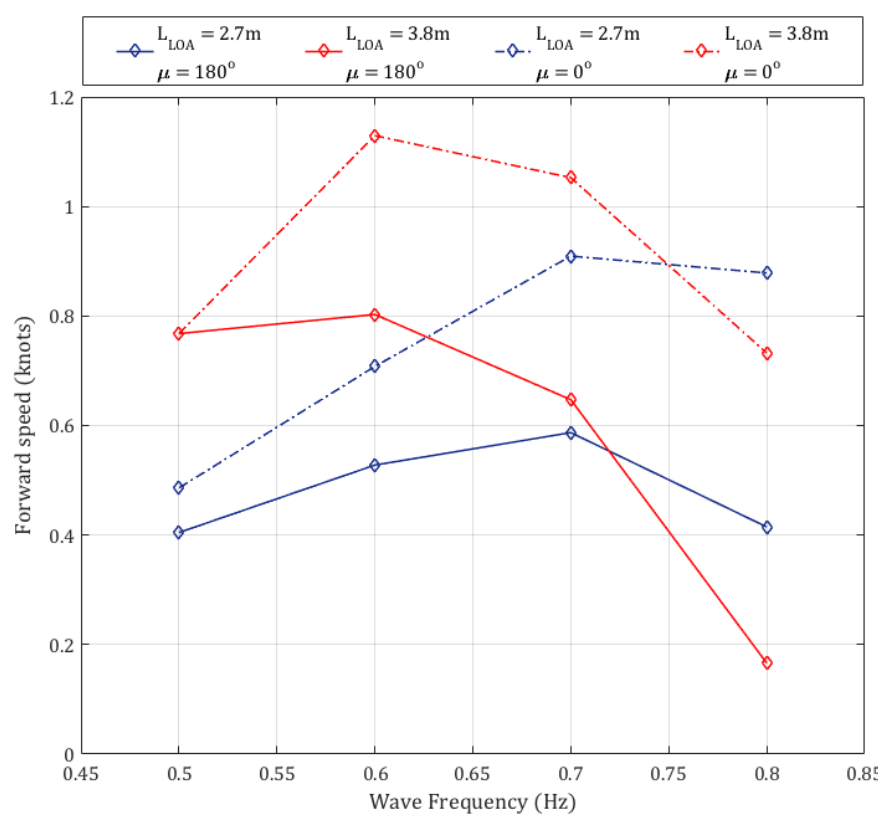

Figure 12: Forward speed comparison between the longitudinal location of the foils in head $\left(\mu=180^{\circ}\right)$ and following waves $\left(\mu=0^{\circ}\right) ; \mathrm{H}=0.12 \mathrm{~m}$

speed is significantly greater with extended foils which suggests that an increase in the wave induced flapping foil motion is due to an increase in the moment arm from the LCG.

The forward speed is also very dependent on the 
encountered wave frequency which in turn is a function of the forward speed. As the wave frequency increases there is a substantial increase in the difference between the forward speed for following and head waves. For head waves, at higher wave frequencies $(>0.6 \mathrm{~Hz})$, the surface vehicle is propelled into the waves which increases the encountered wave frequency away from the resonant pitch frequency of $0.6 \mathrm{~Hz}$. This Doppler effect reduces the pitch motion which consequently reduces the wave induced flapping foil propulsion. For following waves, also at higher wave frequencies, the forward speed has the opposite effect; the surface vehicle is propelled away from the incoming waves towards the resonant frequency.

\section{Discussion}

The results identify a significant reduction in the vessel pitch due to the effect of the submerged foils. This is in agreement with previous experiments conducted by Bockmann and Steen (2015) in head waves which highlighted a reduction in pitch of upto $60 \%$ with one foil mounted at the bow [14]. The study by Bockmann and Steen (2015) also identified a significant reduction in heave, which is contrary to the results presented in Figure 8 a). The difference between these results may be attributed to the fact that, in the current experiments, the foils were only mounted at the bow and also at the aft of the vehicle. Therefore, in pitch motion, the lift force generated by the forward and aft foil within one wave period results in moments that act in the same angular direction about the LCG, as shown in Figure 4 a). However, for heave motion, the resultant vertical forces acting on the forward and aft foils effectively oppose each other within one wave period and, therefore, there is a minimal overall effect on the vessel heave motion, as depicted in Figure 4 a).

The free running experiments confirmed a similar effect on the hull motions in head waves due to the longitudinal location of the forward and aft foils; identifying a significant reduction in pitch whilst there is a minimal effect on heave. However, in following waves Figure 9 a), shows that the extended foils effectively reduces the vessel heave with respect to the encountered wave frequency but not the actual wave frequency. In following waves, the foils are orientated away from the incident wave and this may have an effect on the hydrodynamic forces acting on the foils. Further research is required to investigate this interesting outcome.

Figure 13 shows how the relative motion of the submerged foil at the bow drives the permanent magnet through the PMTLG PTO device. At maximum positive vessel pitch the surface vehicle can be seen to work against the submerged foil where the relative displacement between the bow and the foil is reduced. The opposite effect is observed for maximum negative vessel pitch. Therefore, the generated power is related to the local velocities experienced by the surface vehicle at the forward and aft remote locations of the submerged foils. This explains the difference in power generated by the forward and aft foils, highlighted in Figure 10. For the experiments,

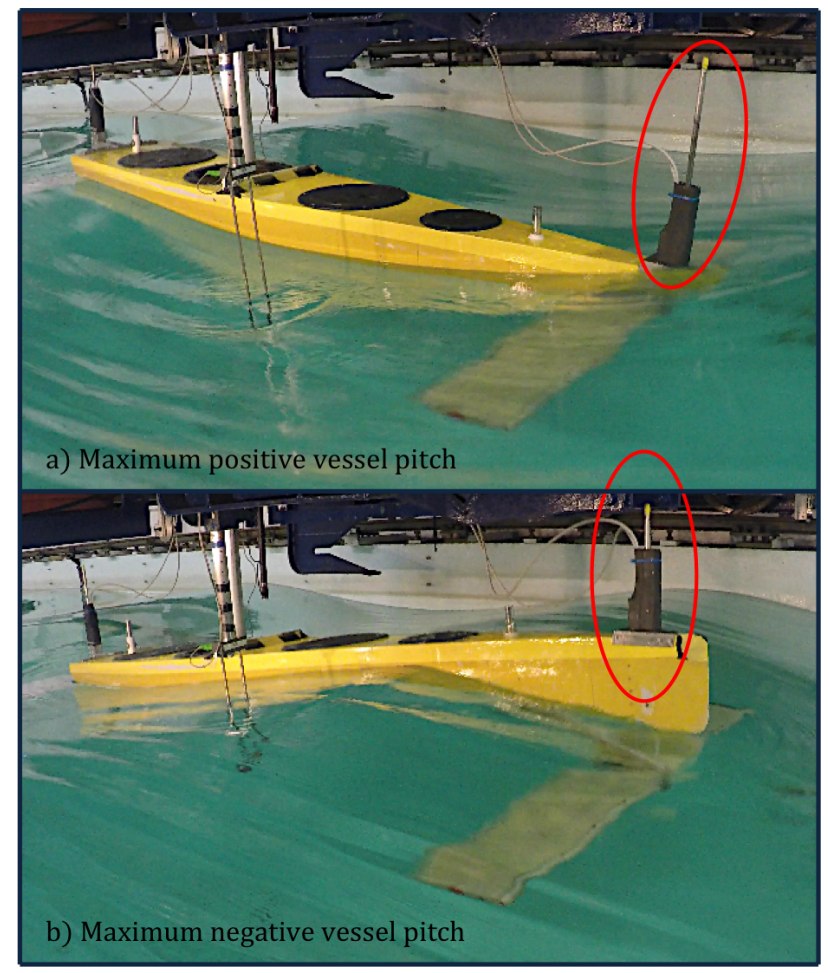

Figure 13: Relative foil and permanent magnet rod heave in regular waves ( $\mathrm{f}=0.7 \mathrm{~Hz}$ and $\mathrm{H}=0.18 \mathrm{~m}$ ) during; a) Maximum positive vessel pitch and b) Maximum negative vessel pitch

the centre of rotation for vessel pitch was fixed at the location where the tow post is secured which was approximately $0.1 \mathrm{~m}$ abaft of the LCG (-0.15 from the amidships). As the tow post fixing was located aft of the LCG, the forward and aft foils were not spaced equally from the LCG. The forward and aft foils were located $1.3 \mathrm{~m}$ and $1.1 \mathrm{~m}$ from the tow post fixing respectively which resulted in differing local velocities at the remote locations. At the aft foil there is, therefore, less pitch induced heave and this is reflected in the power generated as shown in Figure 11. The reduction in power generated by the aft foil may also be attributed to the effect of the forward foil and the hull on the incoming wave energy.

The power generated was shown to be fairly inefficient with a maximum energy recovery efficiency of approximately $2 \%$. However, the PTO requires optimization and the load in the electrical circuit should be tuned to maximise the efficiency of this device. This is highlighted as an important aspect for future work and a common problem in developing ASV wave energy scavenging devices, especially due to the frequency dependent response of the setup. The experiments for energy recovery were also limited by the maximum wave height that could be generated in the towing tank, which is a height of $0.2 \mathrm{~m}$. However, an interesting outcome from the experiments was the proportional relationship between the generated power and wave height. Applying the proportional relationship defined in the previous section, it is possible to extrapolate the power generated in alternative regular waves. 
For example, in a wave height of $0.4 \mathrm{~m}$ and frequency of $0.7 \mathrm{~Hz}$, the forward foil is predicted to generate a maximum of 3 watts and mean of 1 watt. This type of wave energy recovery could potentially contribute to the powering of onboard ASV systems and the recharging of batteries during station keeping scenarios.

The free running experiments identified a significant effect of the longitudinal location of the foils on the forward speed of the vehicle. Whether the effect is positive or negative is dependent on the incident wave frequency which has interesting implications for the design of a wave induced flapping foil propulsor for ASVs. For example, it is evident at lower wave frequencies that extending the longitudinal location of the foils will yield an increase in the propulsive thrust which suggests that the length of a pitch induced wave propelled vessel should be optimized for a particular sea area depending on the wave statistics. Also, designing the resonant pitch frequency to produce an optimum response from the flapping foils is regarded as an important development. Ideally, this would need to change with respect to the heading of the surface vehicle.

\section{Vi. Conclusions}

Within the context of wave energy recovery and propulsion, the experiments described here have highlighted the importance of several factors that influence the response of submerged flapping foils onboard ASVs. Most notable of these, is that the foils have a significant effect on the vessel which, in this case, can be regarded as the main wave energy converter. In terms of implications for ASVs, optimum seakeeping characteristics and foil location should be combined to maximise the conversion of wave energy for propulsion and onboard power generation.

\section{ACKNOWLEDGEMENTS}

This research is supported by the Lloyd's Register Foundation.

\section{REFERENCES}

[1] Isshiki, H., "A theory of wave devouring propulsion (1st Report) - Thrust generation by a linear Wells turbine." J. Soc. Naval Arch. Japan, (151):5464. 1982

[2] Isshiki, H., "A theory of wave devouring propulsion (2nd Report) - Optimized foil motions for a passive-type wave devouring propulsor.” J. Soc. Naval Arch. Japan, (152):89100, 1982.

[3] Isshiki, H., and Murakami, M., "A theory of wave devouring propulsion (3rd Report) - An experimental verification of thrust generation by a passive-type hydrofoil propulsor." J. Soc. Naval Arch. Japan, (154):118128, 1983.

[4] Isshiki, H., and Murakami, M., "A theory of wave devouring propulsion (4th Report) - A comparison between theory and experiment in case of a passive-type hydrofoil propulsor." J. Soc. Naval Arch. Japan, (156):102114, 1984.

[5] MOST (AV) Ltd, accessed March 2015, ihttp://www.autonautusv.com/specifications

[6] Linden, H., "Improved combination with floating bodies, of fins adapted to effect their propulsion." GB Patent 14,630. Filed Aug. 1, 1895. Patented Jul. 18, 1896.

[7] Jakobsen, E., "The foilpropeller, wave power for propulsion." In Second International Symposium on Wave and Tidal Energy, BHRA Fluid Engineering, pages 363369. 1981.

[8] Manley, J., and Willcox, S., "The Wave Glider: A persistent platform for ocean science." OCEANS 2010 IEEE Sydney, 1, 2010.

[9] Terao, Y., and N. Sakagami. "Design and development of an autonomous wave-powered boat with a wave devouring propulsion system.” Advanced Robotics, vol. 29(1), pp 89-102, 2015.

[10] Townsend, N.C. and Shenoi, R.A., "Feasibility study of a new energy scavenging system for an autonomous underwater vehicle." Autonomous Robots, 1-13, 2015.

[11] Townsend, N., "Self powered Autonomous Underwater Vehicles (AUVs): Results from a gyroscopic energy scavenging prototype." IET Renewable Power Generation, 112. 2016

[12] Brown, P., Hardisty, D., and Molteno, T. C. A.,, "Wavepowered small-scale generation systems for ocean exploration. Proc. Int. Conf. Oceans-Asia Pacific, Singapore, pp.1-6, 2006.

[13] Naito, S., and Isshiki, H., "Effect of Bow Wings on Ship Propulsion and Motions." Applied Mechanics Reviews, vol. 58, pp 253-268, 2005.

[14] Bockmann, E., and Steen, S., "The Effect of a Fixed Foil on Ship Propulsion and Motions." translated by Launceston, Tasmania, Australia. 2015.

[15] Naito, S., Isshiki, H. and Fujimoto, E., "Thrust generation of a Fin Attached to a Ship in Waves." Journal of KSNAJ, vol. 202, pp. 23-29, 1986.

[16] Belibassakis, K.A. and Filippas, E., "Ship propulsion in waves by actively controlled flapping foils." Applied Ocean Research, 52, 1-11, 2015.

[17] Bockmann, E., "Wave propulsion of ships." PhD Thesis, NTNU, Norway, 2015.

[18] Zheng, Z., Huang, P., Gao, D., and Chang, Z., "Analysis of electromagnetic force of the linear generator in point absorber wave energy converters." Journal of Marine Science and Technology, vol. 23(4), pp. 475-480, 2015.

[19] Bowker, J., Townsend, N.C., Tan, M., and Shenoi, R.A., "Experimental study of a wave energy scavenging system onboard autonomous surface vessels (ASVs)." In, OCEANS15 MTS/IEEE Genova, Genova, IT, 2015. 